\title{
Transformational Leadership as a Critical Success Factor for Enterprise Resource Planning System Implementation
}

\author{
Wael A. Agha, Mohmaed A. Ragheb, Ayman Y. Shawky \\ Arab Academy for Science, Technology and Maritime Transport, Alexandria, Egypt \\ Email:waelaah@hotmail.com, ra ghebmm@aast.edu, aymanshawky@a ast.edu
}

How to cite this paper: Agha, W.A., Ragheb, M.A. and Shawky, A.Y. (2019) Transformational Leadership as a Critical Success Factor for Enterprise Resource Planning System Implementation. Open Access Library Journal, 6: e5243. https://doi.org/10.4236/oalib.1105243

Received: February 12, 2019

Accepted: February 25, 2019

Published: February 28, 2019

Copyright $\odot 2019$ by author(s) and Open Access Library Inc.

This work is licensed under the Creative Commons Attribution International License (CC BY 4.0).

http://creativecommons.org/licenses/by/4.0/ (c) (i) Open Access

\begin{abstract}
The successful implementation of an enterprise resource planning (ERP) system has been described as a challenging strategic initiative for many organizations in varied business settings and different organizational cultures. During the past two decades, there has been massive investment in adopting ERP system, in addition to a substantial increase in focusing on the importance of users' acceptance of utilizing such technological technique. Despite the many advantages of successful installing of ERP system demonstrated in literature but still the failure rate of ERP projects is remarkably high. Leaders of ERP implementation projects have the challenge of displaying effective leadership skills and traits to justify strategic and operational decisions taken during implementation of ERP system. To provide better understanding of what may positively influence a successful implementation of ERP system, this research study is an attempt to investigate whether leadership style especially transformational leadership has a significant impact on successful implementation of ERP systems. The theory of transformational and transactional leadership was the foundations for the researched leadership style in this study. A quantitative, non-experimental correlational empirical research strategy examined the degree of significance of the direct relationship between the independent variable of transformational leadership style and the dependent variable, perceived as ERP success. Projects' leaders, executives, information technology, business managers, and end users who involved in adopting and using ERP system within their Egyptian organizations representing various business settings, were the targeted population of this research. Structural Equation Modeling (SEM) was conducted to test the research hypotheses and analyze the findings and results. The results of the study supported the existence of a significant relationship between transformational leadership style and successful implementation of ERP system.
\end{abstract}




\section{Subject Areas}

Information Technologies, Management Information Systems, Management

Organization

\section{Keywords}

Transformational Leadership, Enterprise Resource Planning, ERP Project

\section{Introduction}

Business environment in the last two decades have witnessed remarkable excessive changes in terms of technological advances and globalization of markets. Aggressive worldwide competition has become a key driver to increase the ability of organizations to generate well-timed and accurate data and information in order to survive as a competitive player in the global market [1].

Accordingly organizations are forced to search for effective and innovative leaders with advanced levels of initiative and expressiveness, as well as strong capabilities for smooth adaptation with the new extensive challenging working environments, in addition to the high ability of motivating employees to foster effective and profitable business practices, better solutions to problems, and demonstrate high level of organizational citizenship behaviors [2].

Enterprise Resource Planning (ERP) is classified as one of the most important organizational strategic initiatives and long term investments due to the extensive financial and human resources necessarily required for adopting ERP projects [3] [4]. ERP implementation project is not simply a "computer software project", it is strategic decision and should be approached as such for being integrated applications which have a significant impact on the entire organization [5].

Leadership has been classified as one of the most substantial critical success factors for the implementation of an ERP system. Therefore, organizations are usually seeking to acquire the appropriate type of leaders with effective leadership competencies that are capable to lead members of ERP projects [6] [7] [8] [9].

\section{Enterprise Resource Planning (ERP)}

ERP system is defined as a set of modules or business applications, which integrate different business units at the organization including financial, logistics, manufacturing, and human resources into a strongly integrated one unique system with a shared platform for flow of information through the whole organizational business functions [1] [10] [11] [12] [13].

A well-implemented technology initiative such as an ERP system, if properly utilized, could guide the organizations to the right pathway of how to fully integrate its business processes, provide an effective infrastructure that facilitates 
smooth, accurate and extensive exchanging and sharing of the correct data and information throughout the organization.

Several academics agreed that advantages of acquiring a successful ERP system include process synchronization, comprehensible process flow from one organizational division to the next, and utilization of one shared database that include all transactions and processes [14]-[19].

In the same context ERP systems increase the effectiveness of supply chain, and supplier/customer relationships management, construct efficient business processes in relation to financial performance according to a variety of financial measures, and remarkably contribute in reduction of inventory costs related to operational and capital expenses [20].

\section{Failure of ERP Project Implementing}

On the other side, the main challenge of ERP project is the significant failure rate of its implementation. There is a remarkably high failure rate for ERP implementation projects [20].

Many researches, studies and the majority of authors have declared that the failure rate of ERP implementation projects is up to 90 percent [17] [20] [21]. Similarly, it was argued that large number of organizations is still suffering from the failure of the execution of their ERP projects while other companies have a lot of concerns to get into the implementation phase of ERP systems for being ambiguous regarding the end results [12].

Managers of organizations are facing a tough workforce resistance to the cultural and operational changes resulting from ERP execution, therefore it is recommended that top management should provide excessive efforts to understand the factors behind such resistance by re-identifying ERP users' needs and re-evaluating the applying procedures of adopted change management strategies, in order to find an acceptable fit between both [22].

Researches revealed that implementation of ERP system has different strategies than traditional information systems either organizational, technical, or people strategies. However to ensure implementing ERP system in a successful manner, organizational main strategy should include change strategy development and creating the appropriate change management techniques [23].

\section{ERP Critical Success Factors}

ERP implementation-project success, usually defined as finalizing the project on time, according to the predetermined scope, and within budget [24] [25] [26]. Meanwhile Bintoro [27] added to the above two other success dimensions which are the Users Satisfaction; as their expectations are met through the ERP system and the Business Performance; enhanced or operational efficiency has increased after finalizing the implementation phase. However the researcher assumed that the concern about the additional two dimensions added by Bintoro [27] is related to how accurately the impact of both dimensions on the success of ERP 
project can be measured separately rather than other dimensions.

Execution of an ERP system is a complex process that contains many factors and conditions which can significantly affect successful implementation [28] [29] [30]. The lack of identifying and understanding of these factors could create difficulties through ERP implementation. In the same context the recent literature recommends that a successful ERP implementation usually requires clear identification and effective management of critical factors and their ingredients at every single phase of the implementation process [1].

Several researches have been conducted during the last decade to identify the critical factors that affect the ERP execution success and failure [5] [12] [13] [20] [31]. However the literature so varied regarding the success factors of ERP project and researches were conducted from different and diverse perspectives [32].

In their study concerning successful implementation of ERP projects, Somers [33] highlighted that organizations have to study carefully how to recognize the critical success/failure factors that significantly affect the implementation process of ERP projects and deal with them effectively to ensure that the targeted benefits can be accomplished and failures can be avoided [12] [21].

From another perspective, Gargeya and Brady [34] claimed that the "human factor" and training concept during an ERP implementation have always received the minimal part of consideration. This is due to the wrong perception that this factor doesn't have the biggest quantifiable advantage. This mistake has definitely been one of the main causes of several failed ERP implementation projects. Meanwhile success of ERP projects is relying heavily on human elements such as projects' managers and projects' team members' in terms of efforts and commitment [8] [35].

In the same context, El Sawah, et al., [36] concluded that ERP implementation success is a function of a set of interrelated critical success factors. They reported that the high failure rate of ERP projects in Egypt was resulted by top managers who use ERP ineffectively and narrowing its scope to include only the automation of the organizational existing processes instead of re-engineering them to comply with ERP philosophy.

\section{ERP Critical Failure Factors}

As discussed by Momoh [37] claimed that the most failure factors of ERP implementation projects which received the most attention from researchers are unnecessary customization, absence of change management, dilemma of internal integration, lack of understanding of business needs and requirements in addition to poor data quality, while inadequate support from top management, limited training, hidden cost and misalignment of IT with business, are the following ranking in the researches' citation. They emphasized that ERP solutions are suitable for the organizations that are seeking to gain the benefits of integration among functional divisions and best practices in its information system, 
across the whole organization.

In the same context Peng and Nunes [13] listed some of ERP failure factors including ERP software misfit, poor consultant efficiency, unrealistic expectations concerning benefits from ERP systems, heavy unnecessary customization, lack of or under quality of Business Process Reengineering, poor IT Infrastructure, high turnover rate of project team members, lack of effective communication and too tight project schedule. Despite demonstrating such factors the researcher is arguing that not all of them at the same direction of impact or have the same influence level on the failure of the process of implementing ERP project.

Meanwhile Gargeya and Brady [34] added three main factors that contribute to failure of ERP system implementation which are inadequate internal organizational readiness for change, user training, and inappropriate planning and budgeting. He assumed that factors that participate in ERP success are not essentially the same factors that contribute to ERP failure. Consequently Organizational management should focus on the set of critical success factors that ensure success as well as the critical failure factors that lead to failure.

\section{ERP and Change Management}

Effective practices of change management is considered as one of the most broadly cited ERP implementation success factors, as ERP is a very significant change initiative and excessive effort should be provided to find an appropriate measurement scale for effective communication during change. Although there still problematic issues concerning the most appropriate activities and practices associated with change management inter-correlated with ERP execution [23].

Accordingly some researchers critiqued the top management in several organizations who consider ERP as simple software system and its execution process is mainly a technical challenge, whereas they should consider that ERP system is in essence a change of the way a company manages its operational activities. In this regards the researcher assumed that such approach should carried out by all organizational members as it is not exclusively related to top management only [18].

Concerning the linkage of ERP to organizational change, Kemp and Low [38] concluded that since ERP is viewed as a significant change in the way of doing the business, change management is an essential element of successful ERP implementation as its activities have an important impact on the implementation climate and on the other hand, the implementation climate significantly shapes the effectiveness of the implementation. They claimed that change management activities of ERP system also influence different areas of the organization in different methods. Each part within the organization is provided by a very diverse series of change management activities according to the recognized needs of employees, and that is the reason behind nominating change management as one of the main factors affecting the success of ERP implementation. 


\section{Transformational Leadership}

Despite the growing diversity of leadership theories have assist in generating an academic agenda for leadership research in the new millennium, transformational leadership theory (based on their statistical study) is expressing the dominant form of interest among scholars and still the most studied and discussed leadership theory in the new millennium [39]-[44].

Meanwhile Tung [45] reported that Transformational leadership has certainly developed into an innovative culture and considered as a major factor that significantly participate of achieving the best organizational performance, as transformational leaders are dedicated to accomplish their organizations' goals, and their subordinates also become committed to reaching those same goals.

Transformational leadership style increases the follower's level of maturity and morals as well as the interest in achievement, self-actualization, and the prosperity of others, the organization, and the whole society [46]. Meanwhile Gyensare et al., [44] assumed that transformational Leadership is considered as a successful form of leadership in terms of organizational, industrial and national fields. They concluded that transformational leadership is a key element in decreasing employee turnover intension through stimulating employee affective commitment to their organizations.

In the same context, Jha [47] described transformational leadership as leadership behavior that participate in generating the development of followers' competencies, knowledge, and personality, therefore, facilitate the growth of the leader, group and the organization as well. In another word transformational leadership can be viewed as a platform for employees to ground their self-determined motivations to create positive change, mutual trust, healthy working environment, organizational well-being, and professional as well as personal growth.

The four components of what referred to as a higher order construct of transformational leadership were articulated by Bass et al., [48] as follows:

\section{Idealized Influence:}

These leaders are trusted, admired and esteemed. Followers would like to simulate their leaders. One of the things the leader does to acquire creditability with followers is to make followers' needs have the priority over their own needs. The leader bear risks with followers and he is consistent with ethics, values and principles.

\section{Inspirational Motivation:}

Leaders' behaviors motivate those around them by giving the meaning and challenge to their followers' missions. Individual and team spirit is stimulated. Enthusiasm and optimism are introduced. The leaders give confidence to followers to envision promising future state, which they can eventually envision for themselves.

Intellectual Stimulation:

Leaders arouse their followers to be innovative, imaginative and creative by 
inquiring assumptions, reframing problems, and moving toward old circumstances in new ways. There is no mockery or public criticism of any one or members' mistakes. New ideas and innovative solutions to problems are requested from followers, who are involved in the process of identifying problems and proposing solutions.

\section{Individualized Consideration:}

Leaders take into consideration each individual's need for success and growth by behaving as a coach or counselor. Followers are developed to successively higher levels of potential. New learning opportunities are created along with a supportive climate in which to grow. Individual differences in terms of needs and desires are recognized.

Transformational leadership has a significant impact on overall business outcomes, such as performance, effectiveness, efficiency, success, survival and sustainability [49]. In the same context Brown and May [50] concluded that transformational leadership was observed to be significantly associated with high level of productivity in a large manufacturing organization. In addition that in their empirical study they found that development and training program on transformational leadership concept and methodologies resulted in significant increases in transformational leadership behaviors among first-line supervisors.

\section{Transformational vs. Transactional \& Laissez-Faire Leadership}

Bass et al., [48] argued that transactional leadership formulate the relationships between leaders and followers based on determining expectations, explaining responsibilities, negotiating contracts, and submitting recognition and rewards for accomplishing expected performance. While Transformational leadership improves the development of followers, challenging them to re-think in different ways in which they are not used to go through, inspiring them to achieve beyond what they considered was possible, and motivating them to do so by holding the values and high ethical standards that guide their behaviors [48] [49] [50] [51].

As recommended per their conducted research Erkutlu [46] proposed that although transactional leadership is targeting the expected outcomes, transformational leadership aims to accomplish performance that exceeds well beyond what is expected. He proposed a meta-analysis of 39 studies in the transformational leadership literature done by Lowe et al. (1996) who concluded that individuals who practiced transformational leadership were apparent to be more effective leaders with better performance outcomes than were individuals who performed only transactional leadership. These results were valid for leaders at higher and lower levels as well as for public and private sectors. One of the main characteristics described the difference between transformational and transactional leadership styles that the transformational leadership behaviors are relationship oriented meanwhile transactional leadership behaviors are task oriented [46].

The fundamental essence of transactional leadership is motivating followers based on applying an efficient and visibly agreed reward system for accomplish- 
ing predefined goals, or utilizing discussed and accepted punishment techniques if specific goals are not achieved [52].

Consequently, transactional leadership demonstrates three constructs: contingent reward, management-by-expectation (negative active or passive forms) [53]. According to contingent reward, a leader provides recognition or other positive compensation to followers when predetermined goals are achieved; therefore, contingent reward is relying on the leader's ability to communicate effectively with expectations [48].

Transactional leadership effect is limited to its impact on the level of the transactional agreement between leader and his subordinate; meanwhile any sort of encouragement to exceed follower performance beyond this level can be generated from transformational leadership practice. Also transactional leadership definition explains the reward method, when followers have exerted additional efforts essential for completing the tasks.

Meanwhile Laissez-faire type of leadership represents a style of a leader who is simply not engaged in the practices of leadership and avoids participating in the decision making related to work activities under his supervision as well as other responsibilities associated with his/her position [41].

Laissez-Faire leaders are always avoiding taking responsibility for their actions, and most frequently are not available when they are needed by their subordinates, usually do not provide their followers with their own opinion on significant topics and often do not deliver any support or assistance to their subordinates when needed [52]. Laissez-Faire leaders are generally avoiding close relationships with their followers, and it is considered the most apathetic style of leadership where the leader does not exert any managerial efforts towards his/her subordinates to achieve organizational goals [52].

Bass et al., [48] considered laissez-faire leadership style as one of the seven constructs of transactional and transformational leadership, arguing that laissez-faire leadership style cannot hold on its own for long time. Therefore, it must be consolidated with other more robust and energetic forms of leadership close to transformational or transactional leadership to become more effective.

\section{Transformational Leadership and Change}

The growing pace of change faced by organizations has increased the demand for more adaptive, flexible leadership as adaptive leaders participate more efficiently in speedily changing environments by assisting to rationally recognize the challenges confronted by leaders and followers and subsequently responding to those challenges in an appropriate way [48]. They also declared that transformational leadership is expressing the essence of adaptive leadership.

While Sloyan et al., [54] advised that during the change process employee recognize trust in leadership by the belief that the leaders of the firm are acting in the best interest of the organization. Employees who have a high degree of trust in organizational leadership tend to maintain positive interaction with the 
change initiative at a greater level. Moreover, leadership support perceived by the individuals is positively affecting the employee's acceptance of organizational change.

In their empirical study Binci et al., [55] concluded that during radical change they observed the existence of transformational leadership style in relation to change initiatives in organization, meanwhile in incremental change they observed the presence of transactional and empowering leadership styles. While Yang and Islam [56] reported that transformational leadership is a major source for providing an internal business advantage as when employees react positively to change due to the influence of transformational leadership's behaviors, such state provides a very important organizational advantage.

\section{Transformational Leadership and Innovation}

Chang [57] confirmed the relationship between transformational leadership and innovation management at the unit level as well as the firm level through the mediating role of trust at the unit level and the empowerment at the firm level. These trusting relationships directly forming the motivation and behaviors of individuals who may perform as change agents for unit innovation.

Also trusting relationship among employees in the same unit reassures those employees about reciprocating knowledge, which is often considered as an important source of innovation. Meanwhile the empowerment context that transformational leadership provides to employees, encourage sharing information and knowledge gained from their diversified experiences, which present generating new ideas for innovation management [57].

Researches on the relationship between leader behavior and individual innovation have concluded the significant influence of transformational leadership style on employees' innovative behaviors. As transformational leaders encourage followers to analysis problems in different and new ways and assist them to perform to their full potential, which result in enhancing their level of creativity [58].

In the same context Nusair et al., [59] confirmed that one of the most recognized leadership styles that have been viewed as appropriate for the current dynamic environment and to improve organizational innovation is transformational leadership, through the high level of motivation that posted among employees through applying its conceptualities. They reported that several empirical studies have proved the positive association between transformational leadership and followers' innovative behavior in related organizations. A concluded research studies on 408 Spanish organizations the significant relationship between transformational leadership and high level of performance through its positive influence on fostering organizational learning and innovation [60].

\section{Transformational Leadership and ERP}

Numerous researches have highlighted the essential leadership traits and skills 
needed by information system project managers and leaders to ensure success, likewise the ability to supervise people, stress control, emotional intelligence discipline and effective communication [35].

Rezvani, et al., [9] concluded in their study that a qualified leader is a critical factor to the success of the ERP implementation in terms of ERP project team performance, clarifying that the result of their study showed the significant relation between transformational leadership practices and high level of ERP team project cohesiveness and consequently its positive effect on the overall project team performance.

ERP implementation success is positively associated with the existence of these dimensions of organizational culture. They added that organizational culture can be consciously designed and well managed by leadership [7].

Meanwhile several researches concluded the strong relationship between transformational leadership and long term performance which is resulted from the deep involvement of transformational leaders in the change process of organizational culture and create a cohesive culture in their organization that is aligned with their vision [48].

Through the empirical results of their research, Shao, et al., [61] concluded the significance of transformational leadership in generating the desired organizational culture and supporting individuals' implicit and explicit knowledge sharing intention, hence to attain business objectives through the assimilation of ERP systems, clarifying that by proving the positive and direct relation between transformational leadership and organizational culture which has both direct and indirect impact on ERP success thought fostering knowledge sharing among employees.

Garg [62] advised that Transformational leadership is considered as a critical success factor associated to ERP implementation projects. He claimed that as the leader who involved in ERP projects should continually strive to resolve conflicts and deal with resistance of change, thus effective change management is crucial during such initiatives, starting at the beginning of the project phase and enduring throughout the entire life cycle, considering that transformational leadership is the most fit form to manage change during the ERP projects specially when dealing with change in enterprise wide culture.

Meanwhile [8] claimed the significant relationship between Chief Executive Officer transformational leadership style in an organization and improvement of organizational performance in the context of an ERP project implementation.

According to Rezvani, et al., [9] the influence of transformational leadership on ERP users through its four constructs is articulated as follows:

- Idealized influence-leaders who have high levels of moral and ethical manner can influence an ERP users' intention to implement or continue to use an ERP system by generating loyalty from followers and more personal respect.

- Inspirational motivation-Leaders with an apparent vision for the future based on organizational norms can motivate ERP users to keep on using the 
system by providing confidence via symbolic behaviors and convincing language.

- Intellectual stimulation-Leaders can encourage ERP users to practice different way of thinking by challenging organizational rules ad polices and drive ERP users to create innovative strategies for the support of continuance of ERP usage.

- Individualized consideration-Leader's behaviors can attempt recognizing the growth and developmental needs of ERP users via training and consulting with them to keep on using ERP. Also such leaders encourage continuous intention of followers to use ERP system by maintaining feedback and associating users' existing needs to the organization's goal.

According to Shao, et al., [63] transformational leadership is one of the critical success factors of ERP projects. They concluded through the empirical results of their research among 101 companies that have implemented ERP systems for at least one year the important role that transformational leadership plays in the field of learning ERP systems among the individuals, through either the positive mediating or the positive direct effect of transformational leadership on organizational learning culture.

The theoretical model of this study illustrated in Figure 1 is demonstrating the relationship between transformational leadership as an independent variable that has four constructs namely idealized influence (B/A) (II), inspirational motivation (IM), intellectual stimulation (IS), individualized consideration (IC) and the success of enterprise resource planning system as a dependent variable.

The rationale underlying this theoretical framework suggests that transformational leadership four constructs affect ERP system successful implementation differently. It is clarified as follow: First, there is a positive association between idealized influenced behaviors/attributes and success of ERP system implementation. Second, there is an affirmative relation among intellectual stimulation behaviors and success of ERP system implementation. Third, the linkage between inspirational motivation behaviors and success of ERP system implementation is positive. Finally, there is a positive association between individualized consideration behaviors of transformational leadership and success of ERP system implementation.

\section{Research Hypotheses}

Creswell [64] explained that the directional hypotheses is applicable for quantitative research method when the investigator provide a prediction concerning the expected results, this prediction is in accordance with prior literature and previous researches on the topic that suggests a potential outcome.

According to the above demonstrated literature review, the following hypotheses were formulated:

$\mathrm{H}_{1}$ : Performing Transformational leadership style's practices has a significant relationship with ERP Successful implementation. 


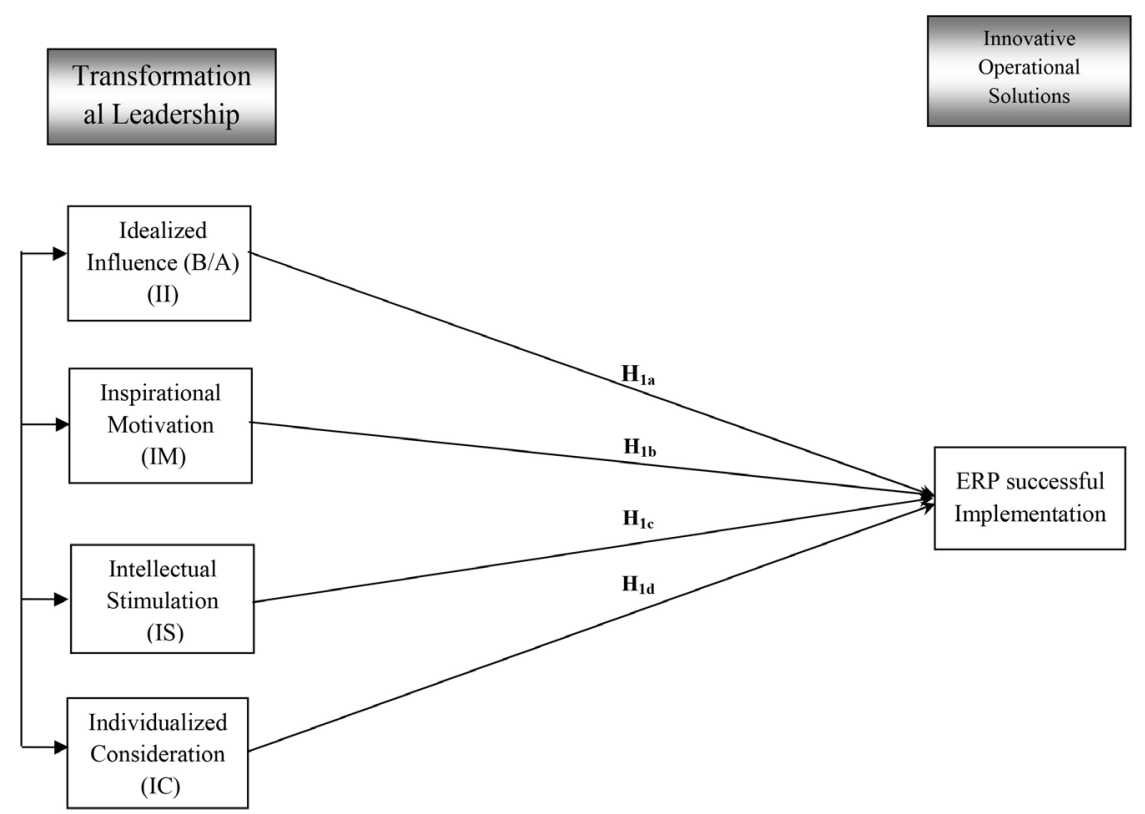

Figure 1. Hypothesized framework.

$\mathrm{H}_{1 \mathrm{a}}$ : Idealized Influence has a significant relationship with ERP Successful implementation.

$\mathrm{H}_{1 \mathrm{~b}}$ : Inspirational Motivation has a significant relationship with ERP Successful implementation.

$\mathrm{H}_{1 \mathrm{c}}$ : Intellectual Stimulation has a significant relationship with ERP Successful implementation.

$\mathrm{H}_{1 \mathrm{~d}}$ : Individualized Consideration has a significant relationship with the success of the implementation of ERP system.

\section{Population and Sample}

The data gathering process targeted participants from Egyptian organizations involved in various business activities such as Computer Software, Oil and Gas, Automotive, Chemicals, Real Estate, FMCG, Governmental organizations and others.

The expected population of such targeted individuals extracted from 70 Egyptian organizations that are well known that they successfully implemented ERP projects with an average of 700 potential users/professionals involved in implementing and using of ERP systems.

Simple random sampling method was chosen as a sampling technique for this research study as the survey attempt to select a sample representing a population in a random manner, in which each member of the population has the same probability of being chosen. In addition that research findings and results concluded from employing of simple random sampling technique can be generalized on the targeted population due to representativeness of this sampling method in addition that such sampling technique is much lower relevance of bias [64]. 
Although it was anticipated that approximately 400 respondents will participate in the investigation of the current study and will finalize the online survey, only 210 participants successfully completed the survey at the end of the collecting data process. However, the typical rate of response concerning online surveys is ranging from $30 \%$ to $60 \%$ out of the targeted population [64]. There for total number of respondents is considered at the acceptable percentage that represents the targeted population.

\section{Instruments and Measures}

Survey questionnaire was the selected instrument for the current study being the most suitable one for collecting the desired data and information concerning topics of this study. Surveys instrument provide a method of acquiring data about predetermined targeted groups of people by using a selected sample representing a population, through focusing on collecting numeric data about current events, asking questions, tabulating and analyzing answers [65].

\section{Justifications for the Electronic Survey Method}

An online survey was an optimal selection for the study, as employing an online tool to conduct the survey questionnaire increases the possibility of capturing a large volume of responses due to the tremendous increase is possessing online access, without significant constrains in terms of time and location [66]. Furthermore, online surveys provide a wide range of advantages such as easy accessibility and editing, in addition to high response rate, as well as honest response, and lower cost for administration [67] [68].

Taking in consideration that all the targeted participants mentioned above expected to have access to the internet as dealing with ERP systems necessitates using the internet, knowing as well that online survey is one of the most feasible choices for several research projects and has been recorded as one of the most usable tool for collecting survey data [69].

Accordingly a well-known online survey tool (Google Format) that has a good reputation in providing advanced, secured and robust survey systems, that allows users to generate and transmit surveys in addition to analyzing and evaluating results, was chosen to be used in collecting the data from the invited persons for being easy to use and not time-intensive for responding, with no direct communication with the researcher.

\section{Multifactor Leadership Questionnaire (MLQ)}

Meanwhile multifactor Leadership questionnaire (MLQ) is the widely known instrument that measure transformational leadership and has been employed in studying leadership styles in numerous institutions which yielded better results in comparison with other instruments [42].

To measure transformational leadership (independent variable), the researcher employed the short version of the multifactor leadership questionnaires MLQ-6S 
short form developed by [52]. MLQ Form $6 \mathrm{~S}$ has been used in numerous research studies [70] [71] [72] [73] [74].

Tejeda et al., [75] argued that MLQ form 6S is viewed as one of the most frequent, validated and well researched leadership measuring instrument in the field of organizational science [70]. In addition that this measure is applicable to be used not only at different organizational settings but also in different cultures contexts.

The MLQ-S6 comprises of 21 questions with 7 leadership factors measuring transformational, transactional, laissez faire leadership behaviors, on a 5-point Likert scale type starting with "not at all", "once in a while", "sometimes", "fairly often", and finally "frequently if not always".

In the MLQ-6S, each factor has 3 items; transformational leadership (TFL) represented through four-dimensional subscales namely idealized influence (II), inspirational motivation (IM), individualized consideration (IC), and intellectual stimulation (IS). As for transactional leadership (TAL), 6 items are divided into two subscales: contingent reward (CR, 3 items) and management by exception (ME, 3 items). Meanwhile, laissez-faire leadership (LFL) measured through 3 items only.

\section{ERP Success Measure}

The DeLone and McLean [76] IS Success model (D\&M Model) is the most widely cited in the field of IS research. In fact, 285 articles from the top information system journals referred to and made used of the model between the year 1993 to the mid 2002 [77].

Gable et al., [78] examined the notion of measuring success of information systems in multiple dimensions and advised that despite that researches examining the success of information systems have been ongoing for approximately three decades [79], a seldom consensus was noted either among practitioners or researchers on the most convenient measures of information systems success over three decades, hindering development of a cumulative research tradition.

Gable et al., [78] model for measuring success of information system was developed based upon the widely accepted information system success measurement model "D\&M model" introduced by DeLone and McLean [76]. A-priori IS-Impact measurement model of Gable et al., [78] is consisting of two portions-the Impact portion symbolized by the Individual-Impact and Organizational-Impact dimensions, and the Quality portion introduced by the System-Quality and Information-Quality dimensions.

\section{Testing the Research Hypotheses by Structural Equation Modeling}

The following are the results of applying structural equation modeling technique using AMOS (Analysis of Moment Structure), being one of the most widely used 
software application applying SEM statistical technique in the social sciences researches [80] [81].

\section{SEM Analysis for Relationship between Transformational Leadership Constructs and ERP Successful Implementation}

The SEM model conducted for testing the direct relationship between Transformational Leadership constructs and ERP successful implementation is illustrated in Figure 2.

Table 1 shows the SEM analysis of the impact of transformational Leadership on ERP successful implementation. It could be observed that the model fit indices; CMIN/DF (Chi-square/degree of freedom) $=1.532$, GFI (Goodness of Fit Index $)=0.952$, CFI (Comparative Fit Index $)=0.984$, AGFI (Adjusted Goodness of Fit Index $)=0.914$, and RMSEA (Root mean square error of approximation $)=$ 0.50 are all within their acceptable levels [82].

Also it is noted that there is a positive significant impact of Inspirational Motivation (IM), and Individual Consideration (IC) on ERP successful implementation, as the estimates are 0.422 and 0.411 as well as P-value is less than 0.05 .

Meanwhile for Idealized Influence (II) and Intellectual Stimulation (IS) show insignificant relations with ERP successful implementation as p-values are greater than 0.05 .

These findings partially support the research hypotheses $\mathrm{H} 1$ regarding the significant relation between Transformational Leadership constructs and ERP successful implementation, as the results of SEM test accepted the hypotheses $\mathrm{H} 1 \mathrm{~b}$ and $\mathrm{H} 1 \mathrm{~d}$ that Inspirational Motivation, and Individual Consideration have positive significant relationship with ERP successful implementation and in the same time the SEM test rejected hypotheses $\mathrm{H} 1 \mathrm{a}, \mathrm{H} 1 \mathrm{c}$ that Idealized Influence and Intellectual Stimulation has significant relationship with ERP successful implementation.

However, the R square is 0.504 , which means that the model explains $50.4 \%$ of the variation in ERP Successful implementation.

\section{Discussion of Direct Relation between Transformational Leadership Constructs and ERP Successful Implementation}

This section will discuss the results and findings of conducted SEM analysis for the direct relation between transformational leadership four constructs and ERP successful implementation through the tested hypotheses $\mathrm{Hla}, \mathrm{H} 1 \mathrm{~b}, \mathrm{H} 1 \mathrm{c}$ and H1d.

\section{Discussing of Relation between Idealized Influence to ERP Success}

H1a: Idealized Influence has a significant relationship with ERP Successful implementation. 


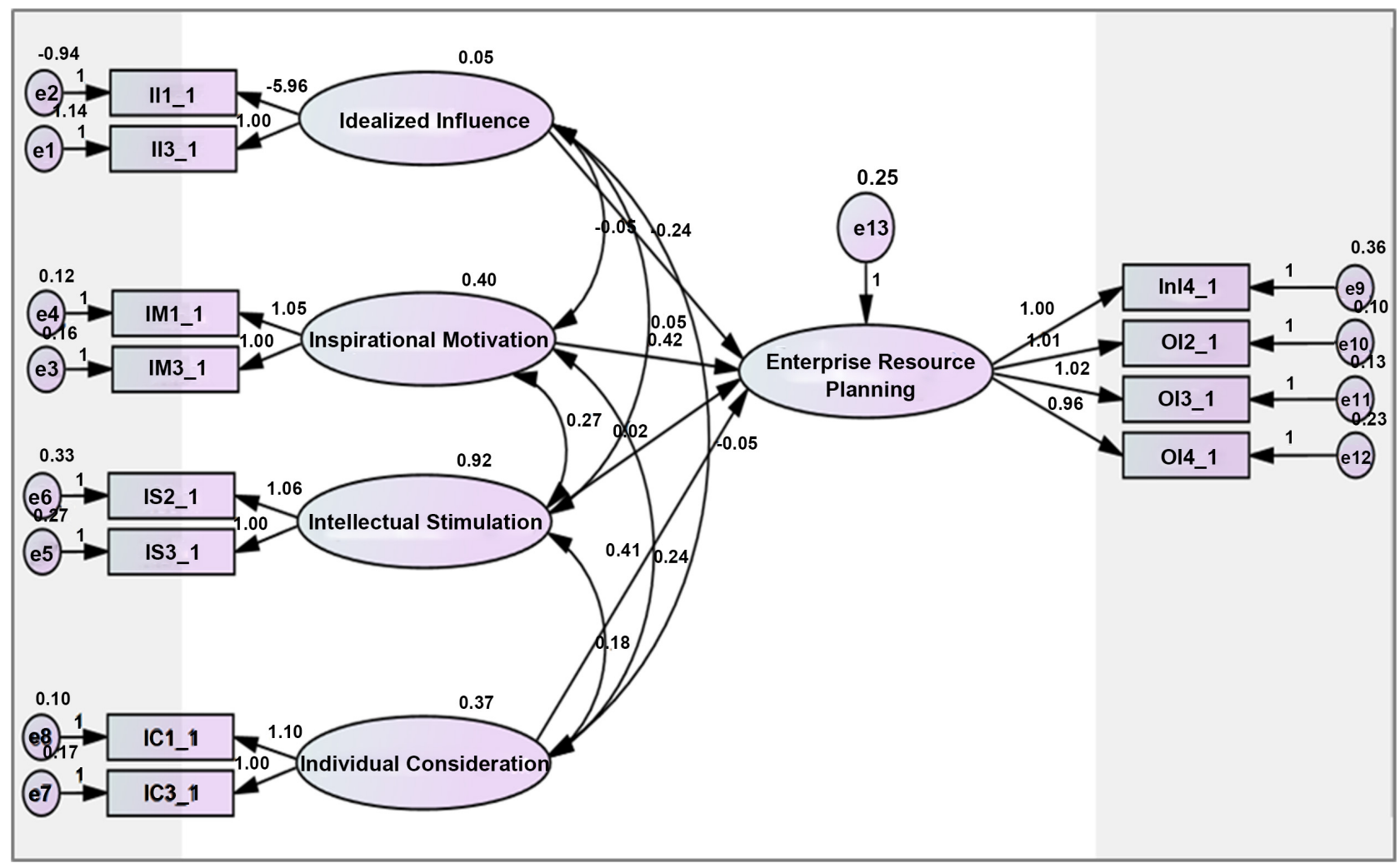

Figure 2. SEM analysis of relation between TFL and ERP Successful implementation.

Table 1. SEM Analysis of relation between TFL and ERP successful implementation.

\begin{tabular}{cccccc}
\hline & & & Coeff. & P-value & R-square \\
\hline $\begin{array}{c}\text { ERP Successful } \\
\text { Implementation }\end{array}$ & $<---$ & Idealized Influence (II) & -0.238 & 0.051 & \\
ERP Successful & $<--$ & Inspirational Motivation (IM) & 0.422 & $* * *$ & \\
Implementation & & & & 0.504 \\
ERP Successful & $<---$ & Intellectual Stimulation (IS) & 0.021 & 0.671 & \\
Implementation & & & & & \\
$\begin{array}{c}\text { ERP Successful } \\
\text { Implementation }\end{array}$ & $<---$ & Individual Consideration (IC) & 0.411 & & \\
\hline
\end{tabular}

The results of the SEM analysis show no support for $\mathrm{H} 1 \mathrm{a}$ as the p-value is greater than 0.05 and the coefficient showing a negative value -0.238 which presents an inverse relation between Intellectual Stimulation and ERP successful implementation.

The results related to this hypothesis could reflect respondents' belief that the idealized influence behavior which they obtained from the leaders at their organizations is vital but in another context rather than ERP. As such practices that of idealized influence are not enough to participate in the success of implementing a complex system such as ERP. In other words, respondents' of this group have the belief that implementing such sophisticated information system that of ERP necessitates leaders to provide their subordinates with more than 
just talking about the most important values and ethics.

Such results are not complying with the research study conducted by Ke and Wei [7] claiming that managerial leaders can renovate their followers from a personal oriented, self-indulgent, rational-economic mode of operation to a collective, ethical and value-oriented mode of operation, in order to energize them to exert efforts and show commitment to future information technology innovation adoption. Also SEM results for this hypotheses are not matching with what Rezvani, et al., [9] and Chang [57] concluded in their researches that leaders who practice idealized influence and have high levels of moral and ethical manner can influence their subordinates to effectively participate in ERP system by generating loyalty and more personal respect.

\section{Discussing of Relation between Inspirational Motivation to ERP Success}

H1b: Inspirational Motivation has a significant relationship with ERP Successful implementation.

The results of the SEM analysis display full support for $\mathrm{H} 1 \mathrm{~b}$ as the $\mathrm{p}$-value is less than the level of significant 0.05 . It implies that the Inspirational Motivation behavior as a construct of transformational leadership style has significant relationship to ERP successful implementation.

Such results exhibit respondents' belief that when a leader provides a clear vision about why the organization choose to implement ERP system, what are the expected benefits, and to what extend the working conditions will be improved after deploying ERP system, in addition to defining clearly the goals and objectives that associated directly with employees themselves and demonstrate all of these issues with optimism and enthusiasm, such leader's behavior will generate confidence through the employees that there will be more chance for successful implementation of ERP system.

From another perspective managers in organizations must appreciate that firms are in need to establish a clear, understandable and stable vision. As when a leader is capable of articulating a compelling vision of an organization future, followers are consequently motivated. Such motivation, then, energizes them to attain their highest potentials; accordingly they will assist the organization in its quest for improvement.

SEM analysis of this hypothesis is reflecting the conclusion of the research study conducted by Rezvani, et al., [9] that leaders with an apparent vision for the future based on organizational norms can motivate employees to be positively involved in ERP system by providing confidence via symbolic behaviors and convincing language.

Furthermore, the results of SEM analysis are complying with what [23] [48] [62] concluded in their researches that ERP is highly correlated to organizational change and change management process, thus leaders should practice inspirational motivation behavior to generate a culture of change in their working en- 
vironment as such culture can assist in successfully implementing the ERP system.

\section{Discussing of Relation between Intellectual Stimulation to ERP Success}

H1c: Intellectual Stimulation has a significant relationship with ERP Successful implementation.

The results of the SEM analysis display no support for H1c as the p-value is greater than 0.05. It implies that the Intellectual Stimulation behavior as a construct of transformational leadership style has no significant relationship to ERP successful implementation.

Such results are surprisingly observed by the researcher who assumed that pursuing differing approaches in solving problems and viewing working conflicts from several different angles enable organizations to overcome the complexity of the implementation process of such sophisticated information technology system that of ERP which proven through the demonstrated previous researches in the literature review chapter.

These results are disagreeing with what [9] [58] concluded in their research that intellectual stimulation as a dimension of transformational leadership is positively associated to followers' innovation implementation behavior.

More precisely, when a leader presents intellectual stimulation, followers are motivated to re-questioning some of their previous assumptions, the status quo of the working processes, and old ways of doing things, accordingly followers are more likely to recognize and focus on the positive results of new initiatives such as implementing ERP system instead of on concerns and worries.

However, the reason behind such results could be relying on respondent's belief that the received behaviors from their leaders through intellectual stimulation practices are ambiguous and not directly connected to the unique nature of problems and conflicts associated with the process of implementing ERP system. In other words respondents need more guidance and advice from their leaders of how they should seek different perspectives in regard of solving problems.

Also respondents may believe that leaders in addition to encourage employees to questioning the status quo of the organization, they should draw the road maps for doing so and they may consider that just providing an appreciation offered by the leaders against suggesting new ways of doing business processes or generating new ideas of how to finalize certain assignments in ERP context is not enough to have a significant impact on the success of the project.

\section{Discussing of Relation between Individualized Consideration and ERP Success}

H1d: Individualized Consideration has a significant relationship with ERP Successful implementation.

The results of the SEM analysis show full support for H1d as the p-value is 
greater than 0.05. It implies that the Individualized Consideration behavior as a dimension of transformational leadership style has significant relationship to ERP successful implementation.

The reason behind this support as the SEM results reflect respondents' belief that leaders when supporting their subordinates to develop their skills and competencies and seeking to fulfill their operational and personal needs so that they could attain their maximum potentials, such behavior have a direct association with successful implementation of ERP system.

Accordingly, respondents believe that there is a significant linkage between individualized consideration behavior as a component of transformational leadership and ERP successful implementation specifically, when the leader behave as an advisor and coach, taking into account that each individual has different needs and abilities.

Also SEM analysis of this hypotheses is complying to what Rezvani et al., [9] concluded that through practicing individualized consideration construct of transformational leadership, leaders can recognize the growth and developmental needs of their followers in ERP context via providing necessary training as well as consulting activities with subordinates to keep them associated and involved in ERP phases either pre-implementation, during implementation or post-implementation stages.

Additionally, such findings through conducted SEM analysis are matching with what Shao, et al., [63] concluded through their empirical study that transformational leadership through its construct of individualized consideration plays and important role in the field of learning ERP systems among employees, through either the positive mediating or the positive direct effect of transformational leadership on organizational learning culture.

Finally the results of SEM analysis displayed that the direct relation between independent variable (Transformational Leadership constructs) and the dependent one (ERP successful implementation) is significant as the R-square is 0.504 meaning that the model is proving that $50.4 \%$ of the variation in the ERP successful implementation is explained by the positive impact of transformational leadership style.

As shown above this research study concluded that transformational leadership is the most appropriate and effective style for implementing ERP system in the context of the targeted population under this study.

These findings of subject study are important in several ways as discussed in the following sections.

\section{Theoretical Implications}

As far as the researcher knows, this study is the first attempt in the Egyptian context that conceptualized and empirically examined the transformational leadership constructs (idealized influence, inspirational motivation, intellectual stimulation and individualized consideration) in relation to ERP successful implementation. This study will add substantial knowledge to the body of research 
in both fields of leadership and enterprise resource planning.

The findings of this research study are complying with the literature that supports the existence of significant association between transformational leadership and ERP success [7] [9] [61]. In addition of giving a shed of light that transformational leadership could be recognized as one of the critical key factors that has positive impact on the successful execution of ERP system in addition to the various CSFs demonstrated in the chapter two of literature review.

Academics and researchers will find in this study informative portions in a well-organized sequence about the relation of ERP and multiple dimensions of leadership and management in organizational settings.

In addition this study highlighted the important and crucial role of human factor in regards of organizational strategic initiatives that necessitate a high level of effective change management practices such as information system projects.

This study provided two separate sections focusing on the relationship between transformational leadership and change management for which Binci et al., [55] concluded that during radical change they observed the existence of transformational leadership style in relation to change initiatives in organization, meanwhile in incremental change they observed the presence of transactional and empowering leadership styles.

The other section is displaying the association between enterprise resource planning and the concept of organizational change for which establishing innovation projects such as ERP implementation contains uncertainty and insecurity due to the potential need for change in the organization as well as the necessitate of complying with new operational standards that ERP provoke.

\section{Practical Implications}

Although it is considered that leadership style contribute with a vital role in the success of information technology implementation, the most appropriate style of leadership that ERP projects leaders displayed during system implementation had never been clear.

Although ERP project managers and leaders can utilize transformational leadership strategies to effectively inspire, stimulate, and motivate their subordinates, they would also require embracing appropriate transactional leadership practices. In other word, project leaders in addition to their transformational leadership activities they should be able to create a precise and clear plan, present rewards and penalties, and effectively arrange and control the company-wide support.

Because ERP system implementation is viewed as a process through which organizations introduce an innovative operational solutions into the workforce community [2]. Studying the differentiated impacts of various leadership styles will provide a richer, advanced and more integrated understanding about which is the most leadership styles that will support and promote successful implementation of an ERP project. 
The study offers a better understanding of the influence of transformational leadership style in ERP implementation in the Egyptian context. The findings when considered could lead to improved leadership training in ERP implementation, which in turn assist in reducing the failure rate of implementation of such complicated and highly expensive project.

The researcher strongly recommends in view of the finding of this study that ERP project managers and leaders to be extensively trained on project leadership and how to acquire its competencies and skills, considering that lack of training may result that project managers usually practice a set of leadership approaches and activities that do not eventually lead to the success of ERP project implementation.

One of the most important practical implications of this study that managers and leaders involved in ERP implementation process need to be self-aware regarding their behaviors and actions and continuously perform a self-assessment by being aware of their limitations and take the necessary action for better improvement of their leadership skills and competences. Also they should pay more attention to effectively manage and control their emotions and be confident about of their abilities to lead their subordinates to the success of ERP project.

Also this study reveals that leaders who used teamwork or seek to build effective, creative, productive and committed teams need to be more transparent. This displays leaders as honest, trustworthy, and also have integrity, which facilitate the project team to obtain trust in leaderships being the most significant and critical competencies for leaders to possess.

However, project managers and organizational leaders in charge of ERP project implementation are able to benefit from the results and findings of this research study in several ways according to their different business setting and cultural in order to effectively manage leadership challenges they are facing during the process of ERP implementation.

\section{Conclusions of the Study}

Organizations are seeking to adopt enterprise resource planning system as a main strategy for implementing business technological applications that comply with the needs of the users' community in organizations and promote advanced information system architecture aiming for future organizational growth.

Generally when implementing an ERP system, the prospects of leaders and managers are to redesign business processes if applicable, improve communications, reduce operational costs, and achieve a considerable return on investment which has not been achieved due to the high failure rate of ERP projects. On the other hand, in the lack of knowledge regarding the most appropriate leadership behaviors, organizational leaders and mangers could fail to promote the desired business environment that generates greater business performance and sustainable success. 
The growing high failure rates of the implementation of ERP projects (Shah et al., 2011), participated in exploring the need for this study, which attempts to provide organizational leaders as well as practitioners in charge of ERP projects with an alternative leadership strategy that may contribute toward satisfactory and effective implementing of ERP system.

Several investigations in the research field of leadership styles concluded that a transformational leader is the most one who can establish and engage an effective team in order to perform in excellent manner toward a specific vision for an organization such as successful implementation of ERP.

This study concluded that leaders in organizations necessitate to take advantage of transformational leadership practices and behaviors to make sure that ERP implementation is on the right way and the expected outcomes and benefits are attained.

Transformational leaders attempt to catalyze their subordinates to be highly involved and effectively engaged in tasks of ERP implementation. They pay a great attention to each individual's personal, operational and developmental needs as they work jointly and cooperatively to attain organization goals expected from acquiring such information system.

By behaving as coaches, mentors, and consultants, leaders support and assist their followers to achieve their potentials. In addition, such leaders also exercise contingent rewards as a construct of transactional leadership to motivate their followers to effectively participate in implementing as ERP system.

\section{Conflicts of Interest}

The authors declare no conflicts of interest regarding the publication of this paper.

\section{References}

[1] Beheshti, H.M., Blaylock, B.K., Henderson, D.A. and Lollar, J.G. (2014) Selection and Critical Success Factors in Successful ERP Implementation. Competitiveness Review, 24, 357-375. https://doi.org/10.1108/CR-10-2013-0082

[2] Hernandez, R. (2014) The Impact of Emotional Intelligence and Leadership Style on ERP Implementations in the Retail Industry. Doctoral Dissertation, Capella University, Capella.

[3] Stewart, R.A. (2008) A Framework for the Life Cycle Management of Information Technology Projects. International Journal of Project Management, 26, 203-212. https://doi.org/10.1016/j.ijproman.2007.05.013

[4] Cereola, S.J., Wier, B. and Norman, C.S. (2010) Impact of Top Management Team on Firm Performance in Small and Medium-Sized Enterprises Adopting Commercial Open-Source Enterprise Resource Planning. Behaviour \& Information Technology, 31, 889-907. https://doi.org/10.1080/0144929X.2010.528029

[5] Dezdar, S. and Sulaiman, A. (2009) Successful Enterprise Resource Planning Implementation: Taxonomy of Critical Factors. Industrial Management \& Data Systems, 109, 1037-1052. https://doi.org/10.1108/02635570910991283

[6] Boersma, K. and Kingma, S. (2005) Developing a Cultural Perspective on ERP. Business Process Management Journal, 11, 123-136. 
https://doi.org/10.1108/14637150510591138

[7] Ke, W. and Wei, K.K. (2008) Organizational Culture and Leadership in ERP Implementation. Decision Support Systems Journal, 45, 208-218.

https://doi.org/10.1016/j.dss.2007.02.002

[8] Huang, C.M., Hsu, P.Y. and Chiau, W.L. (2011) Perception of the Impact of Chief Executive Leadership Style on Organizational Performance through Successful Enterprise Resource Planning. Social Behavior \& Personality: An International Journal, 39, 865-878. https://doi.org/10.2224/sbp.2011.39.7.865

[9] Rezvani, A., Khosravi, P. and Nazir, A.M. (2012) Assessing the Role of Transactional and Transformational Leadership in Continuance Intentions of Enterprise Resource Planning. Pacific Asia Conference on Information Systems (PACIS 2012) Proceedings, Paper 75. http://aisel.aisnet.org/pacis2012/75

[10] Beheshti, H.M. (2006) What Managers Should Know about ERP/ERP II. Management Research News, 29, 184-193. https://doi.org/10.1108/01409170610665040

[11] Garg, P. and Garg, A. (2013) An Empirical Study on Critical Failure Factors for Enterprise Resource Planning Implementation in Indian Retail Sector. Business Process Management Journal, 19, 496-514. https://doi.org/10.1108/14637151311319923

[12] Ali, M. and Miller, L. (2017) ERP System Implementation in Large Enterprises: A Systematic Literature Review. Journal of Enterprise Information Management, 30, 666-692. https://doi.org/10.1108/JEIM-07-2014-0071

[13] Peng, G.C. and Nunes, M. (2017) Establishing an Evidence-Based 9D Evaluation Approach for ERP Post-Implementation. Industrial Management \& Data Systems, 117, 398-424. https://doi.org/10.1108/IMDS-03-2016-0087

[14] Nah, F.F.H., Lau, J.L.S. and Kuang, J. (2001) Critical Factors for Successful Implementation of Enterprise Systems. Business Process Management Journal, 7, 285-296. https://doi.org/10.1108/14637150110392782

[15] Umble, E.J., Haft, R.R. and Umble, M.M. (2003) Enterprise Resource Planning: Implementation Procedures and Critical Success Factors European. Journal of Operational Research, 146, 241-257. https://doi.org/10.1016/S0377-2217(02)00547-7

[16] Gyampah, K.A. (2004) ERP Implementation Factors: A Comparison of Managerial and End User Perspectives. Business Process Management Journal, 10, 171-183. https://doi.org/10.1108/14637150410530244

[17] Žabjek, D., Kovačič, A. and Štemberger, M.I. (2009) The Influence of Business Process Management and Some Other CSFs on Successful ERP Implementation. Business Process Management Journal, 15, 588-608. https://doi.org/10.1108/14637150910975552

[18] Pishdad, A. and Haider, A. (2013) ERP Institutionalization: Exploring the Influential Factors. Journal of Enterprise Information Management, 26, 642-660. https://doi.org/10.1108/JEIM-07-2013-0046

[19] Garg, P. and Khurana, R. (2017) Applying Structural Equation Model to Study the Critical Risks in ERP Implementation in Indian Retail. Benchmarking: An International Journal, 24, 143-162.

[20] Saade, R.G. and Nijher, H. (2016) Critical Success Factors in Enterprise Resource Planning Implementation: A Review of Case Studies. Journal of Enterprise Information Management, 29, 72-96. https://doi.org/10.1108/JEIM-03-2014-0028

[21] Garg, P. and Garg, A. (2014) Factors Influencing ERP Implementation in Retail Sector: An Empirical Study from India. Journal of Enterprise Information Man- 
agement, 27, 424-448. https://doi.org/10.1108/JEIM-06-2012-0028

[22] Aladwani, A.M. (2001) Change Management Strategies for Successful ERP Implementation. Business Process Management Journal, 7, 266-275.

https://doi.org/10.1108/14637150110392764

[23] Finney, S. and Corbett, M. (2007) ERP Implementation: A Compilation and Analysis of Critical Success Factors. Business Process Management Journal, 13, 329-347. https://doi.org/10.1108/14637150710752272

[24] Liu, A.Z. and Seddon, P.B. (2009) Understanding How Project Critical Success Factors Affect Organizational Benefits from Enterprise Systems. Business Process Management Journal, 15, 716-743.

[25] Ram, J. and Corkindale, D. (2014) How "Critical" Are the Critical Success Factors (CSFs)? Examining the Role of CSFs for ERP. Business Process Management Journal, 20, 151-174. https://doi.org/10.1108/BPMJ-11-2012-0127

[26] Panayiotou, N.A., Gayialis, S.P., Evangelopoulos, N.P. and Katimertzoglou, P.K. (2015) A Business Process Modeling-Enabled Requirements Engineering Framework for ERP Implementation. Business Process Management Journal, 21, 628-664. https://doi.org/10.1108/BPMJ-06-2014-0051

[27] Bintoro, B.P.K., Simatupang, T.M., Putro, U.S. and Hermawan, P. (2015) Actors' Interaction in the ERP Implementation Literature. Business Process Management Journal, 21, 222-249. https://doi.org/10.1108/BPMJ-11-2013-0142

[28] Al-Jabri, I.M. (2015) Antecedents of User Satisfaction with ERP Systems: Mediation Analyses. Kybernetes Journal, 44, 107-123. https://doi.org/10.1108/K-05-2014-0101

[29] Abu-Shanab, E., Abu-Shehab, R. and Khairallah, M. (2015) Critical Success Factors for ERP Implementation: The Case of Jordan. International Arab Journal of E-Technology, 4.

[30] Jagoda, K. and Samaranayake, P. (2017) An Integrated Framework for ERP System Implementation. International Journal of Accounting \& Information Management, 25, 91-109. https://doi.org/10.1108/IJAIM-04-2016-0038

[31] Amid, A., Moalagh, M. and Ravasan, A.Z. (2012) Identification and Classification of ERP Critical Failure Factors in Iranian Industries. Information Systems Journal, 37, 227-237. https://doi.org/10.1016/j.is.2011.10.010

[32] Dezdar, S. and Ainin, S. (2011) Examining ERP Implementation Success from a Project Environment Perspective. Business Process Management Journal, 17, 919-939. https://doi.org/10.1108/14637151111182693

[33] Somers, T.M., Nelson, K. and Ragowsky, A. (2000) Enterprise Resource Planning (ERP) for the Next Millennium: Development of an Integrative Framework and Implications for Research. Proceedings of the Americas Conference on Information Systems, Long Beach, CA, 998-1004.

[34] Gargeya, V.B. and Brady, C. (2005) Success and Failure Factors of Adopting SAP in ERP System implementation. Business Process Management Journal, 11, 501-516. https://doi.org/10.1108/14637150510619858

[35] Wang, E., Chou, H.W. and Jiang, J. (2005) The Impacts of Charismatic Leadership Style on Team Cohesiveness and Overall Performance during ERP Implementation. International Journal of Project Management, 23, 173-180. https://doi.org/10.1016/j.ijproman.2004.09.003

[36] El Sawah, S., Tharwat, A.A.F. and Rasmy, M.H. (2008) A Quantitative Model to Predict the Egyptian ERP Implementation Success Index. Business Process Management Journal, 14, 288-306. https://doi.org/10.1108/14637150810876643 
[37] Momoh, A., Roy, R. and Shehab, E. (2010) Challenges in Enterprise Resource Planning Implementation: State of the Art. Business Process Management Journal, 16, 537-565. https://doi.org/10.1108/14637151011065919

[38] Kemp, M.J. and Low, G.C. (2008) ERP Innovation Implementation Model Incorporating Change Management. Business Process Management Journal, 14, 228-242. https://doi.org/10.1108/14637150810864952

[39] Shin, S.J. and Zhou, J. (2007) When Is Educational Specialization Heterogeneity Related to Creativity in Research and Development Teams? Transformational Leadership as a Moderator. Journal of Applied Psychology, 92, 1709-1721. https://doi.org/10.1037/0021-9010.92.6.1709

[40] Dinh, J.E., Lord, R.G., Gardner, W.L., Meuser, J.D., Liden, R.C. and Hu, J. (2014) Leadership Theory and Research in the New Millennium: Current Theoretical Trends and Changing Perspectives. The Leadership Quarterly, 25, 36-62. https://doi.org/10.1016/j.leaqua.2013.11.005

[41] Gilbert, S., Horsman, P. and Kelloway, E.K. (2016) The Motivation for Transformational Leadership Scale: An Examination of the Factor Structure and Initial Tests. Leadership \& Organization Development Journal, 37, 158-180. https://doi.org/10.1108/LODJ-05-2014-0086

[42] Brandt, T., Laitinen, E.K. and Laitinen, T. (2016) The Effect of Transformational Leadership on the Profitability of Finnish Firms. International Journal of Organizational Analysis, 24, 81-106. https://doi.org/10.1108/IJOA-03-2014-0744

[43] Weiß, E.E. and Süß, S. (2016) The Relationship between Transformational Leadership and Effort Reward Imbalance. Leadership \& Organization Development Journal, 37, 450-466. https://doi.org/10.1108/LODJ-08-2014-0146

[44] Gyensare, M.A., Tsede, O.A., Sanda, M.A. and Okpoti, C.A. (2016) Transformational Leadership and Employee Turnover Intention: The Mediating Role of Affective Commitment. World Journal of Entrepreneurship, Management and Sustainable Development, 12, 243-266. https://doi.org/10.1108/WJEMSD-02-2016-0008

[45] Tung, F.C. (2016) Does Transformational, Ambidextrous, Transactional Leadership Promote Employee Creativity? Mediating Effects of Empowerment and Promotion Focus. International Journal of Manpower, 37, 1250-1263. https://doi.org/10.1108/IJM-09-2014-0177

[46] Erkutlu, H. (2008) The Impact of Transformational Leadership on Organizational and Leadership Effectiveness: The Turkish Case. Journal of Management Development, 27, 708-726. https://doi.org/10.1108/02621710810883616

[47] Jha, S. (2014) Transformational Leadership and Psychological Empowerment: Determinants of Organizational Citizenship Behavior. South Asian Journal of Global Business Research, 3, 18-35. https://doi.org/10.1108/SAJGBR-04-2012-0036

[48] Bass, B.M., Avolio, B.J., Jung, D.I. and Berson, Y. (2003) Predicting Unit Performance by Assessing Transformational and Transactional Leadership. Journal of Applied Psychology, 88, 207-218. https://doi.org/10.1037/0021-9010.88.2.207

[49] Jyoti, J. and Dev, M. (2015) The Impact of Transformational Leadership on Employee Creativity: The Role of Learning Orientation. Journal of Asia Business Studies, 9, 78-98. https://doi.org/10.1108/JABS-03-2014-0022

[50] Brown, W. and May, D. (2012) Organizational Change and Development: The Efficacy of Transformational Leadership Training. Journal of Management Development, 31, 520-536. https://doi.org/10.1108/02621711211230830

[51] Krishnan, V.R. (2012) Transformational Leadership and Personal Outcomes: Em- 
powerment as Mediator. Leadership \& Organization Development Journal, 33, 550-563. https://doi.org/10.1108/01437731211253019

[52] Bass, B.M. and Avolio, B.J. (1990) Developing Transformational Leadership: 1992 and Beyond. Journal of European Industrial Training, 14, 21-27. https://doi.org/10.1108/03090599010135122

[53] Bass, B.M. (2000) The Future of Leadership in Learning Organizations. Journal of Leadership \& Organizational Studies, 7, 18-40. https://doi.org/10.1177/107179190000700302

[54] Sloyan, R.M. and Ludema, J.D. (2015) That's Not How I see It: How Trust in the Organization, Leadership, Process, and Outcome Influence Individual Responses to Organizational Change. Research in Organizational Change and Development, 18, 233-277. https://doi.org/10.1108/S0897-3016(2010)0000018011

[55] Binci, D., Cerruti, C. and Braganza, A. (2016) Do Vertical and Shared Leadership Need Each Other in Change Management? Leadership \& Organization Development Journal, 37, 558-578. https://doi.org/10.1108/LODJ-08-2014-0166

[56] Yang, Y.F. and Islam, M. (2012) The Influence of Transformational Leadership on Job Satisfaction: The Balanced Scorecard Perspective. Journal of Accounting \& Organizational Change, 8, 86-402. https://doi.org/10.1108/18325911211258353

[57] Chang, Y. (2016) Multilevel Transformational Leadership and Management Innovation: Intermediate Linkage Evidence. Leadership \& Organization Development Journal, 37, 265-288. https://doi.org/10.1108/LODJ-06-2014-0111

[58] De Jong, J.P.J. and Den Hartog, D.N. (2007) How Leaders Influence Employees' Innovative Behavior. European Journal of Innovation Management, 10, 41-64. https://doi.org/10.1108/14601060710720546

[59] Nusair, N., Ababneh, R. and Bae, Y.K. (2012) The Impact of Transformational Leadership Style on Innovation as Perceived by Public Employees in Jordan. International Journal of Commerce and Management, 22, 182-201. https://doi.org/10.1108/10569211211260283

[60] Morales, V., Montes, F. and Jover, A. (2008) The Effects of Transformational Leadership on Organizational Performance through Knowledge and Innovation. British Journal of Management, 19, 299-319. https://doi.org/10.1111/j.1467-8551.2007.00547.x

[61] Shao, Z., Feng, Y. and Liu, L. (2012) The Mediating Effect of Organizational Culture and Knowledge Sharing on Transformational Leadership and Enterprise Resource Planning Systems Success: An Empirical Study in China. Computers in Human Behavior, 28, 2400-2413. https://doi.org/10.1016/j.chb.2012.07.011

[62] Garg, P. (2010) Critical Success Factors for Enterprise Resource Planning Implementation in Indian Retail Industry: An Exploratory Study. International Journal of Computer Science and Information Security, 8.

[63] Shao, Z., Feng, Y. and Hu, Q. (2013) The Impact Mechanism of Transformational Leadership Style on Exploitative and Exploratory Learning of ERP Systems. 17th Pacific Asia Conference on Information Systems, Jeju Island, 18-22 June 2013, 12. http://lib.dr.iastate.edu/scm_conf/12

[64] Creswell, J.W. (2014) Research Design: Qualitative, Quantitative, and Mixed Methods Approaches. 4th Edition, SAGE Publications, Inc., Thousand Oaks.

[65] Leedy, P. and Ormrod, J. (2010) Practical Research Planning and Design. 9th Edition, Pearson, Boston.

[66] Lee, G., Benoit-Bryan, J. and Johnson, T.P. (2012) Survey Research in Public Ad- 
ministration: Assessing Mainstream Journals with a Total Survey Error Framework. Public Administration Review, 72, 87-97. https://doi.org/10.1111/j.1540-6210.2011.02482.x

[67] Evans, J.R. and Mathur, A. (2005) The Value of Online Surveys. Internet Research Journal, 15, 195-219. https://doi.org/10.1108/10662240510590360

[68] Sentosa, I., Chee, W.M., Bambang, B.S. and Nik-Kamariah, N.M. (2012) A Structural Equation Modeling of Internet Banking Usage in Malaysia. Researchers World Journal, 3, 75-86.

[69] Sue, V.M. and Ritter, L.A. (2012) Conducting Online Surveys. 2nd Edition, SAGE, Thousand Oaks. https://doi.org/10.4135/9781506335186

[70] Vinger, G. and Cilliers, F. (2006) Effective Transformational Leadership Behaviours for Managing Change. South African Journal of Human Resources Management, 4, 1-9. https://doi.org/10.4102/sajhrm.v4i2.87

[71] Song, J.H., Kolb, J.A., Lee, U.H. and Kim, H.K. (2012) Role of Transformational Leadership in Effective Organizational Knowledge Creation Practices: Mediating Effects of Employees' Work Engagement. Human Resource Development Quarterly, 23, 65-101. https://doi.org/10.1002/hrdq.21120

[72] Qosja, E. and Druga, E. (2014) The Higher Education Institution in Albania and Its Leadership Style Challenge. The Macrotheme Review, 3.

[73] Bagheri, R., Sohrabi, Z. and Moradi, E. (2015) Psychometric Properties of Persian Version of the Multifactor Leadership Questionnaire (MLQ). Medical Journal of Islam Republic of Iran, 29, 256.

[74] Baek, H., Byers, E.H. and Vito, G.F. (2018) Transformational Leadership and Organizational Commitment in Korean Police Station: Test of Second-Order MLQ-6 S and OCQ. International Journal of Police Science \& Management, 20, 155-170. https://doi.org/10.1177/1461355718774582

[75] Tejeda, M.J., Scandura, T. and Pillai, R. (2001) The MLQ Revisited Psychometric Properties and Recommendations. Leadership Quarterly, 12, 31-52. https://doi.org/10.1016/S1048-9843(01)00063-7

[76] DeLone, W.H. and McLean, E.R. (1992) Information Systems Success: The Quest for the Dependable Variable. Information Systems Research, 3, 60-95. https://doi.org/10.1287/isre.3.1.60

[77] DeLone, W.H. and McLean, E.R. (2003) The Delone and Mclean Model of Information Systems Success: A Ten Years Update. Journal of Management Information Systems, 4, 9-30.

[78] Gable, G., Sedera, D. and Chan, T. (2008) Re-Conceptualizing Information Systems Success: The IS Impact Measurement Model. Journal of Information Systems, 9, 377-408.

[79] Gable, G., Sedera, D. and Chan, T. (2003) Enterprise Systems Success: A Measurement Model. 24th International Conference of Information Systems, Naples, 16-21 June 2003, 576-591.

[80] Streiner, D.L. (2006) Building a Better Model: An Introduction to Structural Equation Modelling. The Canadian Journal of Psychiatry, 51, 317-324. https://doi.org/10.1177/070674370605100507

[81] Guo, B., Perron, B.E. and Gillespie, D.F. (2009) A Systematic Review of Structural Equation Modeling in Social Work Research. British Journal of Social Work, 39, 1556-1574. https://doi.org/10.1093/bjsw/bcn101

[82] Kline, R.B. (2011) Principles and Practice of Structural Equation Modeling. 3rd Edition, Guilford Press, New York. 